\title{
A Constitutive Model for Yield Strength and Work Hardening Behaviour of Aluminium Alloys during Artificial Ageing
}

\author{
Kang Ji ${ }^{1, *}$, Guanfeng Li ${ }^{1}$, Yongbao Sun ${ }^{1}$, Jia Xu ${ }^{1}$, Hui Chen ${ }^{1}$, Kaiyan Chen ${ }^{1}$, Yan Zhu ${ }^{1}$ \\ and Yong $\mathrm{Li}^{2}$ \\ 1 Beijing Institute of Astronautical Systems Engineering, Beijing 100076, China; ligfcharles@163.com (G.L.); \\ a8583159@126.com (Y.S.); xj167@163.com (J.X.); chenhui3036042@163.com (H.C.); \\ chenkaiyan_kevin@163.com (K.C.); allanmarry@sina.com (Y.Z.) \\ 2 School of Mechanical Engineering and Automation, Beihang University, Beijing 100191, China; \\ liyong19@buaa.edu.cn \\ * Correspondence: jerryji1989@gmail.com; Tel.: +86-10-88520445
}

Received: 14 July 2020; Accepted: 8 August 2020; Published: 13 August 2020

\begin{abstract}
In this study, a unified constitutive model has been developed for both yield strength and work hardening behaviour prediction of aluminium alloys with different types of precipitates during and after artificial ageing. The different type and dimensions of general precipitate shapes (sphere, plate, rod) have been classified and modelled by a primary dimension and aspect ratio, with which a general set of equations has been utilised to model the precipitates evolutions during ageing of various aluminium alloys. In addition, the effects of main microstructures on not only yield strength but also work-hardening behaviour of artificially aged aluminium alloys have been considered and modelled, based on which, a whole set of unified constitutive model considering both micro- and macro-properties for long-term artificial ageing of aluminium alloys has been proposed. Artificial ageing of two representative aluminium alloys (an Al-Mg-Si alloy AA6063 and an Al-Cu-Li alloy AA2198) has been adopted to show the capability and effectiveness of the developed model. The results show that the model can successfully predict the microstructures, yield strength and work hardening behaviour of various aluminium alloys with different precipitate types after long-term artificial ageing process, e.g., from $0 \mathrm{~h}$ to $500 \mathrm{~h}$. It is believed that the model can be used for ageing of other aluminium alloys with dominant sphere, plate or rod-shaped precipitates.
\end{abstract}

Keywords: constitutive equations; yield strength; work hardening; artificial ageing; aluminium alloy

\section{Introduction}

Artificial ageing is essential for heat treatable aluminium alloys to achieve the high strength performance for industrial applications [1,2]. The microstructures, such as solid solutes and second phased precipitates, evolves during artificial ageing process. The complex changes of these microstructures, including their levels and dimensions, with different ageing temperatures and time then leads to the complicated evolutions of main mechanical properties of the aged alloys, such as the yield strength and work hardening behaviour, which are key factors need to be considered in the subsequent forming processes or applications [3-5]. Hence, how to model and predict their evolutions during artificial ageing process is of great importance for the potential applications of heat treatable aluminium alloys.

Various studies have been published on the ageing behaviour of commonly used heat treatable aluminium alloys. Marceau et al. [6] investigated the precipitation sequence of an Al-Cu-Mg alloy at early stage of artificial ageing at $150^{\circ} \mathrm{C}$, during which thin clusters have been observed for strengthening. 
The precipitation behaviour of an Al-Cu-Mg alloy was also investigated by Wang et al. [7], and a precipitation sequence of GP zones $\rightarrow \theta^{\prime} \rightarrow \theta / S$ phases was reported. Alexopoulos et al. [8] reported the precipitation kinetics, yield strength and work hardening behaviour of an $\mathrm{Al}-\mathrm{Cu}-\mathrm{Mg}$ alloy, and found that both yield strength and work hardening behaviour were directly affected by the evolving precipitation kinetics during artificial ageing. The precipitation sequence and corresponding yield strength behaviour of 7xxx series $\mathrm{Al}-\mathrm{Zn}-\mathrm{Mg}$ alloys from under-ageing to over-ageing states have also been widely reported, and a precipitation sequence of GP zones $\rightarrow \eta^{\prime} \rightarrow \eta$ phases of the alloys during artificial ageing has been generally accepted [9-11]. The 6xxx series Al-Mg-Si alloys also attracts extensive attention due to their high demand in the automobile industry, and the corresponding precipitation sequence has been summarized as GP zones $\rightarrow \beta^{\prime} \rightarrow \beta$ phases from under-ageing to over-ageing $[12,13]$. Most of the current studies concentrated on the yield strength properties of the artificially aged alloys, while the other main properties, such as work hardening behaviour, attracted fewer attention.

Constitutive modelling is an efficient way for modelling and predicting the artificial ageing process, so as to direct the process design and optimization for particular purposes. Dislocation based models, considering the shearing and bypassing deformation mechanism in the artificially aged alloys, have been widely adopted for modelling of the yield strength evolutions, in which internal variables, such as precipitate radius and solute concentrations have been considered [14-16]. These models have further been updated by the increasing understanding of the detailed evolutions and properties of precipitates during ageing and their contributions to yield strength, and extended to predict aluminium alloys with more complex heat treatable histories [17-19]. As introduced before, different aluminium alloys have their particular precipitates during ageing, which show different geometric properties, e.g., rod-shape for $\beta^{\prime}$ precipitates, sphere-shape for $\eta^{\prime}$ precipitates and plate-shape for $\theta^{\prime}$ precipitates. However, currently, different models were used for different aluminium alloys due to their varying dimensions and evolution progresses of precipitation. In addition, most of the models developed before only considered the microstructures and yield strength properties, while for the other key mechanical properties of the material, such as work hardening behaviour, has not been included. The work hardening behaviour has been widely investigated, and the most common way for modelling is proposed by Kocks [20] with an internal variable approach. The internal variable model has been further modified to include the different effect of microstructures in the alloys, such as precipitation and solid solution [21,22]. Li et al. [23] proposed a unified constitutive model for the microstructures, yield strength and work hardening of an $\mathrm{Al}-\mathrm{Cu}-\mathrm{Li}$ alloy during artificial ageing, and obtained a fair good prediction result. However, the models were particularly developed for Al-Cu-Li alloys with plate-shaped precipitates, and their capability on the prediction of ageing behaviour of other aluminium alloys needs to be further improved.

Hence, this study tries to develop a general form of unified constitutive model for prediction of both microstructures and key mechanical properties (including yield strength and work hardening behaviour) of various aluminium alloys with different precipitate types and with artificial ageing states ranging from under-ageing to over-ageing. The key dimensions affecting the strengthening of different precipitate types in different aluminium alloys have been summarised and converted to a general form of primary dimension and aspect ratio, with which, various aluminium alloys with different precipitate types can be modelled by the same set of equations. The evolutions of microstructures and their different contributions to not only the yield strength but also the work hardening behaviour at different ageing states have been considered and modelled. The model then has been applied to predict the ageing performances of two typical aluminium alloys, an Al-Mg-Si AA6063 and an Al-Cu-Li AA2198, and their calibration procedures and predicting effectiveness have been discussed.

\section{Constitutive Model}

A unified constitutive model considering both micro- and macro-properties of aluminium alloys during and after artificial ageing process has been developed in this study, including the models for the 
microstructures and yield strengths of the alloys during ageing, and for the work hardening behaviour of artificially aged alloys. The details of the models are given in this section.

\subsection{Artificial Ageing Process}

The key microstructures, including precipitation, solid solution, and their corresponding contributions to yield strength properties of aluminium alloys during artificial ageing process are discussed and modelled.

\subsubsection{Microstructures}

(a) Precipitates

Precipitates are the key factors for the strengthening of aluminium alloys during artificial ageing, whose contributions are mainly affected by their dimensions and volume fractions [24,25].

Figure 1 summarises the general type of precipitates in commercial aluminium alloys, such as spherical particles in Al-Zn-Mg alloys [9], plate-shaped ones in Al-Cu-Mg or Al-Cu-Li alloys [26] and rod-shaped precipitates in Al-Mg-Si alloys [16]. In this study, the primary dimension of the precipitates and corresponding aspect ratio values are utilised to consider their effects on strengthening. In order to propose a general modelling way for different type of precipitates (sphere, plate and rod), their primary dimensions and corresponding aspect ratio are defined in Figure 1.
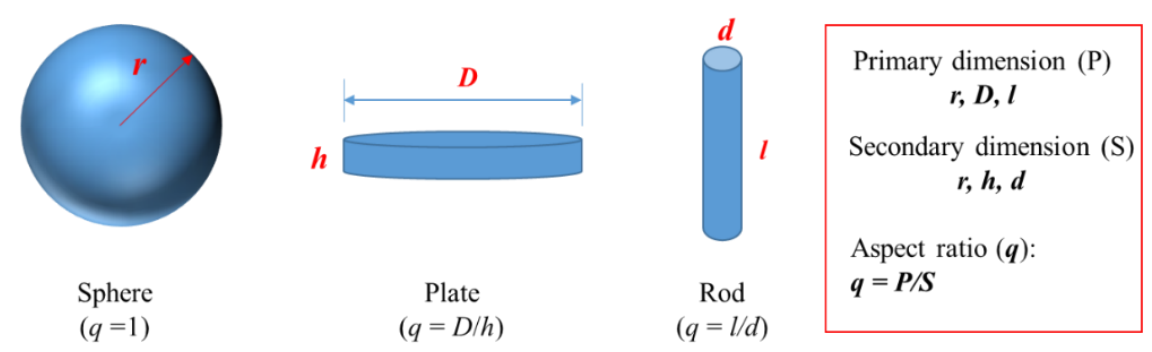

Figure 1. Summary of key dimensions of general precipitates.

In order to simplify the modelling process, all microstructural variables were modelled by their normalised values $[27,28]$ in this study. During artificial ageing, the nucleation, growth and coarsening of precipitates can be modelled by the primary dimension, defined as radius $r_{n}$ in this study (representing $r$ for sphere, $D / 2$ for plate and $l / 2$ for rod in Figure 1 and aspect ratio of $q$.

The evolution of primary dimension of radius during artificial ageing can be modelled by [27]:

$$
\dot{\bar{r}}_{n}=C_{n}\left(Q-\bar{r}_{n}\right)^{m_{1}}
$$

in which, $\bar{r}_{n}=r_{n} / r_{n c}$ is the normalised precipitate radius, where $r_{n c}$ is the critical precipitate radius at the peak-ageing states. $Q, C_{n}$ and $m_{1}$ are material constants for precipitate growth and coarsening.

For spherical precipitates, the aspect ratio $q=1$ during ageing, while for plate- and rod-shaped precipitates, $q$ evolves along ageing states and can be modelled by [29]:

$$
q=\frac{C_{q}}{\exp \left[k_{1}\left(t-t^{*}\right)^{2}\right]}
$$

where $t$ is the ageing time, $t^{*}$ is the critical time for the highest aspect ratio, which generally can be treated as peak-ageing time, $C_{q}$ and $k_{1}$ are material constants.

In addition to the nucleation and growth of new precipitates, there are some conditions that existing clusters or small precipitates existing in the naturally aged alloys may dissolve at the early stages of artificial ageing, which have been widely reported previously [28]. As these are small 
precipitates, only the primary dimension $r_{d}$ is considered in this study to simplify the model, and its evolution can be modelled by its normalised value, as [23]:

$$
\dot{\bar{r}}_{d}=-\frac{C_{d}}{\bar{r}_{d}}
$$

in which $\bar{r}_{d}=r_{d} / r_{d 0}$, where $r_{d 0}$ is the initial radius value of dissolving precipitates, and $C_{d}$ is a material constant.

Due to the small size of dissolving precipitates, the evolution of their volume fraction $\bar{f}_{d}$ can be modelled by the cell-assumption, as [18]:

$$
\bar{f}_{d}=\bar{f}_{d_{0}}\left(\frac{\bar{r}_{d}}{\overline{\bar{r}}_{d_{0}}}\right)^{3}
$$

where $\bar{f}_{d_{0}}$ is the initial value of volume fraction. The total volume fraction $\bar{f}$ of the precipitates then is a combination of nucleated $\left(\bar{f}_{n}\right)$ and dissolved $\left(\bar{f}_{d}\right)$ precipitates, as:

$$
\bar{f}=\bar{f}_{d}+\bar{f}_{n}
$$

(b) Solute concentration

Solid solute is the other key microstructure affecting the strength of aluminium alloys during artificial ageing, and its evolution can be modelled by the solid solution (c), as [30]:

$$
\dot{\bar{c}}=-A_{1}\left(\bar{c}-\bar{c}_{a}\right)
$$

where $\bar{c}=c / c_{0}$ ( $c_{0}$ is the initial solid solution of the alloys), and $\bar{c}_{a}$ is the normalised equivalent solute concentration at the ageing temperature. In addition, if there are dissolution of precipitates during ageing, the dissolved precipitates may also have a contribution to the solute concentration, and have been considered by the following equation [23]:

$$
\dot{\bar{c}}=-A_{1}\left(\bar{c}-\bar{c}_{a}\right)+A_{2} \bar{r}_{d}
$$

The total volume fraction of precipitate then can be modelled by the solid solution values, as:

$$
\bar{f}=\frac{1-\bar{c}}{1-\bar{c}_{a}}
$$

\subsubsection{Yield Strength}

The key microstructural variables modelled in the previous section all contribute to the final yield strength of aluminium alloys during artificial ageing, and their contributions are modelled in this section.

(a) Precipitation hardening

The strengthening effect from the newly nucleated precipitates has been considered and modelled in many studies [16,17], a simple form of the model considering both under-ageing (shearing) and over-ageing (bypass) conditions with the normalised precipitate dimensions has been utilised in this study for modelling, as [31]:

$$
\sigma_{p-n}=\sigma_{r}\left(q f_{n}\right)^{m_{2}}
$$

in which $\sigma_{r}$ represents the contribution of strengthening from primary radius, and can be modelled as:

$$
\dot{\sigma}_{r}=C_{p r} \dot{\bar{r}}_{n}^{m_{3}}\left(1-\bar{r}_{n}^{m_{4}}\right)
$$


For the possible dissolving precipitates during artificial ageing, as their dimensions are generally small and will be sheared through during plastic deformation, their contributions to yield strength can be simply modelled by the strengthening equation with shearing mechanism, as $[15,28]$ :

$$
\sigma_{p-d}=C_{p d} \bar{r}_{d}^{m_{5}}
$$

$C_{p r}, C_{p d}, m_{2}$ to $m_{5}$ in Equations (10) and (11) are material constants.

(b) Solution hardening

The strengthening effects from solid solutes have also been widely reported, and the classic equation is used for modelling in this study, as [30]:

$$
\sigma_{S S}=C_{S S} \bar{c}^{m_{6}}
$$

where $C_{S S}$ and $m_{6}$ are material constant, and $m_{6}$ is generally set as $2 / 3$.

(c) Yield strength

The final yield strength of the artificially aged aluminium alloys then is composed of the strengthening from solid solutes and precipitates, whose contributions can be modelled by a classic mixture law, as:

$$
\sigma_{y}=\sigma_{s s}+\sigma_{p}=\sigma_{s S}+\sqrt{\sigma_{p-d}^{2}+\sigma_{p-n}^{2}}
$$

\subsection{Work Hardening Behaviour}

The work hardening behaviour of the artificially aged alloys directly determine their performance in applications, and will be discussed and modelled in this section.

The work hardening behaviour has been widely investigated and modelled before. In this study, the conventional internal variable models proposed by Kocks and Mecking [32] is utilised and updated by considering the effects from the varying microstructural variables modelled in previous sections.

Work-hardening behaviour is believed to be caused by the dislocation hardening from dislocation-obstacle interactions, and it has been divided into two types of dislocation for the work hardening behaviour considering different obstacles, including statistically stored dislocations from dislocation-weak obstacles interaction and geometrically necessary dislocations from dislocation-hard obstacle interactions [32].

The evolution of static storage dislocations density $\rho_{s S}$ has been modelled by Kock [20], and later, updated by Li et al. [28] by its normalised form $\left(\bar{\rho}_{s s}\right)$ as:

$$
\dot{\bar{\rho}}_{s S}=k_{2}\left(1-\bar{\rho}_{s S}\right) \dot{\varepsilon}_{p}
$$

in which $\bar{\rho}_{s S}=\rho_{s s} / \rho_{s s m}, \rho_{s s m}$ represents the maximum value of $\rho_{s s}$ during plastic deformation, and $\dot{\varepsilon}_{p}$ is the plastic strain rate. Considering the solute concentration effect on the evolution of $\rho_{s S}$, Equation (14) has been updated as [23]:

$$
\dot{\bar{\rho}}_{s S}=k_{2} * \bar{c}^{n_{1}} *\left(1-\bar{\rho}_{s s}\right) \dot{\varepsilon}_{p}
$$

where $k_{2}$ and $n_{1}$ are material constants.

As geometrically necessary dislocations come from dislocation-hard obstacle interactions, during under-ageing conditions, where shearable precipitates play the dominant role in aluminium alloys, few geometrically necessary dislocations would be expected, hence its normalised dislocation density is approximately treated as $\bar{\rho}_{g n}=0$ in this study. When the alloy reaches the peak-ageing states, geometrically necessary dislocations started to be generated during plastic deformation, whose evolution has been modelled with the effects from dimensions of precipitates, as [23]:

$$
\bar{\rho}_{g n}=k_{3} \frac{q}{\bar{r}_{n}}\left[1-\exp \left(-\varepsilon_{p}\right)\right] \quad\left(\bar{r}_{n} \geq 1\right)
$$


With the obtained densities of statistically stored dislocations and geometrically necessary dislocations, the work hardening stress can be modelled by the dislocation hardening equations, as:

$$
\sigma_{w}=C_{w} \sqrt{\bar{\rho}_{s S}+\bar{\rho}_{g n}}
$$

The flow stress during quasi-static tensile tests of the alloys after artificial ageing then can be modelled as:

$$
\sigma_{f}=\sigma_{y}+\sigma_{w}=\sigma_{s s}+\sigma_{p}+\sigma_{w}
$$

\section{Detailed Data and Model Calibration for Artificial Ageing of Aluminium Alloys}

In order to analyse and discuss the effectiveness of the developed model in this study, it has been applied to predict the evolutions of microstructures and macro-properties of two commonly used aluminium alloys during artificial ageing with various times, including an Al-0.46Mg-0.44Si $(w t \%)$ alloy AA6063 and an Al-(2.9-3.5)Cu-(0.8-11)Li alloy (wt\%) AA2198. The detailed data from selected published papers [33-35], which are highly cited with abundant validated microstructures and macro-properties, was utilised for calibration and validation of the proposed model in this study.

The AA6063 alloy was prepared to as-quenched state, and then artificially aged at $185^{\circ} \mathrm{C}$ for $5 \mathrm{~h}$ to reach a T6 state and 2 weeks to a T7 state, the details of the tests can be referred to [33], and the results have been utilised for application in this study. As the alloy was aged with the as-quenched state, only new precipitates are considered for modelling, and the related equations used are summarised in Table 1. As precipitates in the as-quenched alloy can be neglected, the initial value of normalized precipitate radius $\bar{r}_{n 0}$ is set as 0 for modelling, and corresponding strengthening component $\sigma_{p-n 0}$ is treated as 0 as well. While the normalized solute concentration $\bar{c}_{0}$ is set as 1 to represent the supersaturate state of the as-quenched alloy, and the yield strength of the as-quenched material is due to solid solution hardening, which can be directly obtained from tensile testing results. All the initial values of the variables are listed in Table 3.

Table 1. Summary of the constitutive model for ageing of AA6063.

\begin{tabular}{ccc}
\hline Microstructural Models & Yield Strength Models & Work Hardening Models \\
\hline$\dot{\bar{r}}_{n}=C_{n}\left(Q-\bar{r}_{n}\right)^{m_{1}}$ & $\sigma_{p-n}=\sigma_{r}\left(q f_{n}\right)^{m_{2}}$ & $\dot{\bar{\rho}}_{s s}=k_{2} * \bar{c}^{n_{1}} *\left(1-\bar{\rho}_{s s}\right) \dot{\varepsilon}_{p}$ \\
$q=C_{q} / \exp \left[k_{1}\left(t-t^{*}\right)^{2}\right]$ & $\dot{\sigma}_{r}=C_{p r} \dot{\bar{r}}_{n}\left(1-\bar{r}_{n}^{m_{4}}\right)$ & $\bar{\rho}_{g n}=k_{3}\left(q / \bar{r}_{n}\right)\left[1-\exp \left(-\varepsilon_{p}\right)\right]$ \\
$\dot{\bar{c}}=-A_{1}\left(\bar{c}-\bar{c}_{a}\right)$ & $\sigma_{s s}=C_{s s} \bar{c}^{m_{6}}$ & $\sigma_{f}=\sigma_{y}+C_{w} \sqrt{\bar{\rho}_{s s}+\bar{\rho}_{g n}}$ \\
$\bar{f}=(1-\bar{c}) /\left(1-\bar{c}_{a}\right)$ & $\sigma_{y}=\sigma_{s s}+\sigma_{p-n}$ & \\
\hline
\end{tabular}

While the AA2198 was with a naturally aged initial temper of T351, and then artificially aged at $155^{\circ} \mathrm{C}$ for up to $500 \mathrm{~h}$. The details of the tests and results are referred to [34]. As the alloy has been naturally aged before artificial ageing, the existing clusters and precipitates have been reported to be dissolved during the initial stages of ageing [35], and hence, all the equations described in Section 2 have been used for modelling, as summarised in Table 2. The initial values of the key variables were determined with the same method mentioned above for those in Table 1 , in which $\bar{r}_{n 0}$ is set as 0 and $\bar{r}_{d 0}$ is set as 1 , due to existing precipitates were all from natural ageing and will experience dissolving in subsequent artificial ageing [34], corresponding strengthening components were obtained from the tensile testing results of as-quenched alloy and T351 alloy according to Equation (13). All the initial values are listed in Table 2, and more details can be referred to [28]. 
Table 2. Summary of the constitutive model for ageing of AA6063.

\begin{tabular}{ccc}
\hline Microstructural Models & Yield Strength Models & Work Hardening Models \\
\hline$\dot{\bar{r}}_{n}=C_{n}\left(Q-\bar{r}_{n}\right)^{m_{1}}$ & & \\
$q=C_{q} / \exp \left[k_{1}\left(t-t^{*}\right)^{2}\right]$ & $\sigma_{p-n}=\sigma_{r}\left(q f_{n}\right)^{m_{2}}$ & \\
$\bar{f}_{n}=\bar{f}_{-}-\bar{f}_{d}$ & $\dot{\sigma}_{r}=C_{p r} \dot{\bar{r}}_{n}\left(1-\bar{r}_{n}^{m_{4}}\right)$ & $\dot{\bar{\rho}}_{s s}=k_{2} * \bar{c}^{n_{1}} *\left(1-\bar{\rho}_{s s}\right) \dot{\varepsilon}_{p}$ \\
$\dot{\bar{r}}_{d}=-C_{d} / \bar{r}_{d}$ & $\sigma_{p-d}=C_{p d} \bar{r}_{d}^{m_{5}}$ & $\bar{\rho}_{g n}=k_{3}\left(q / \bar{r}_{n}\right)\left[1-\exp \left(-\varepsilon_{p}\right)\right]$ \\
$\bar{f}_{d}=\bar{f}_{d_{0}}\left(\bar{r}_{d} / \bar{r}_{d_{0}}\right)^{3}$ & $\sigma_{s s}=C_{s s} \bar{c}^{m_{6}}$ & $\sigma_{f}=\sigma_{y}+C_{w} \sqrt{\bar{\rho}_{s s}+\bar{\rho}_{g n}}$ \\
$\dot{\bar{c}}=-A_{1}\left(\bar{c}-\bar{c}_{a}\right)+A_{2} \bar{r}_{d}$ & $\sigma_{y}=\sigma_{s S}+\sqrt{\sigma_{p-d}^{2}+\sigma_{p-n}^{2}}$ & \\
$\bar{f}=(1-\bar{c}) /\left(1-\bar{c}_{a}\right)$ & & \\
\hline
\end{tabular}

The model for ageing of both alloys, as listed in Tables 1 and 2, include a series of non-linear differential equations, and hence, cannot be solved analytically. In order to determine the material constants in the model, a two-step (numerical + manual) method has been utilised for fitting and calibration [28]. Firstly, an optimisation method based on evolutionary algorithm, as reported before [18] has been used to determine the initial set of material constants. Then a manual adjustment method has been used to fine tune the constants for a proper fitting and calibration. The obtained material constants for AA6063 and AA2198 are listed in Tables 3 and 4 respectively.

Table 3. Initial values and calibrated materials constants for the model listed in Table 1 for AA6063.

\begin{tabular}{|c|c|c|c|c|c|c|c|c|c|c|}
\hline $\bar{r}_{n 0}$ & $\bar{c}_{0}$ & $\sigma_{p-n 0}$ & $\sigma_{s s 0}$ & $C_{n}$ & $Q$ & $m_{1}$ & $C_{q}$ & $k_{1}$ & $t^{*}$ & $A_{1}$ \\
\hline 0 & 1 & 0 & 57 & 0.12 & 2 & 1.6 & 0.9 & $1 e-5$ & 5 & 0.55 \\
\hline $\bar{c}_{a}$ & $m_{2}$ & $C_{p r}$ & $m_{3}$ & $m_{4}$ & $m_{6}$ & $C_{s s}$ & $k_{2}$ & $n_{1}$ & $k_{3}$ & $C_{w}$ \\
\hline 0.28 & 0.3 & 1400 & 1.2 & 0.21 & 0.67 & 57 & 6.8 & 1.17 & 0.46 & 115 \\
\hline
\end{tabular}

Table 4. Initial values and calibrated materials constants for the model listed in Table 1 for AA2198.

\begin{tabular}{|c|c|c|c|c|c|c|c|c|c|}
\hline $\bar{r}_{n 0}$ & $\bar{r}_{d 0}$ & $\bar{c}_{0}$ & $\sigma_{p-n 0}$ & $\sigma_{p-d 0}$ & $\sigma_{s s 0}$ & $C_{n}$ & $Q$ & $m_{1}$ & $C_{q}$ \\
\hline 0 & 1 & 0.91 & 0 & 52 & 205 & 0.138 & 1.0 & 0.45 & 0.9 \\
\hline$k_{1}$ & $t^{*}$ & $C_{d}$ & $A_{1}$ & $A_{2}$ & $\overline{\boldsymbol{c}}_{\boldsymbol{a}}$ & $m_{2}$ & $C_{p r}$ & $m_{3}$ & $m_{4}$ \\
\hline $1 e-6$ & 16 & 0.2355 & 0.05 & 0.045 & 0.32 & 0.35 & 72.3 & 0.2 & 8.21 \\
\hline$C_{p d}$ & $m_{5}$ & $m_{6}$ & $C_{s s}$ & $k_{2}$ & $n_{1}$ & $k_{3}$ & $C_{w}$ & - & - \\
\hline 52 & 2 & 0.67 & 205 & 1.75 & 2.6 & 0.35 & 425 & - & - \\
\hline
\end{tabular}

\section{Modelling Results and Discussion}

\subsection{AA6063}

Figure 2 show the results of main microstructures of AA6063 during long-term artificial ageing process at $185^{\circ} \mathrm{C}$ from both experiments and modelling results with calibrated material constants in Table 3. The experimental results of microstructures, such as normalized precipitate radius, were quantified by transmission electron microscopy (TEM) observations and nanostructure analysis from [33]. Normalised precipitate radius $\bar{r}_{n}$ increases along the ageing time, and reaches to 1 at around $5 \mathrm{~h}$, which corresponds well with the time to achieve the peak-aged T6 state from experimental results in [33]. After which, $\bar{r}_{n}>1$ and coarsening of precipitates occurs with increasing $\bar{r}_{n}$ until reaching a saturate level eventually. The aspect ratio $q$ is predicted to remain a similar level at the first couple of hours during artificial ageing, and tends to decrease after long-term ageing, which could be due to the coarsening occurs more on the diameter sides of the rod-shaped precipitates in the Al-Mg-Si alloy. The normalized solute concentration $\bar{c}$ and volume fraction $f$ have been predicted with an opposite 
trend, corresponding well with Equation (8). All the predicting results agree well with corresponding experimental results in normalized radius, volume fraction of precipitates and solute concentration, indicating the effectiveness of the developed microstructural model.

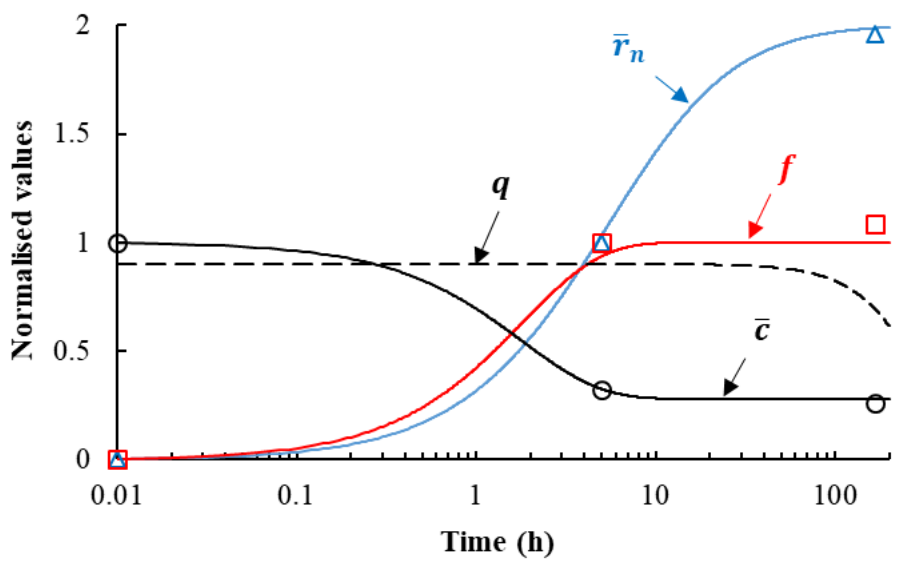

Figure 2. Comparison of evolutions of indicated microstructural variables during artificial ageing of AA6063 at $185^{\circ} \mathrm{C}$ from experiments (symbols [33]) and modelling results from Table 1 (lines).

With the predicted microstructures, the resultant strengthening components and final yield strength have been modelled and compared with corresponding experimental results in Figure 3. A good agreement between the experiments and models in yield strength has been achieved for AA6063 at long-term artificial ageing, again indicating the effectiveness of the developed strengthening model. Solution hardening component $\sigma_{s S}$ experiences the same trend with the solute concentration according to Equation (12). Precipitation hardening component $\sigma_{p-n}$ increases firstly due to the nucleation and growth of precipitates and reaches the peak state at around $5 \mathrm{~h}$, where peak-ageing occurs. After that, $\sigma_{p-n}$ shows a decreasing trend due to the subsequent coarsening of precipitates with further increasing radius and decreasing aspect ratio shown in Figure 2. Both hardening components contribute to the final yield strength of the alloy.

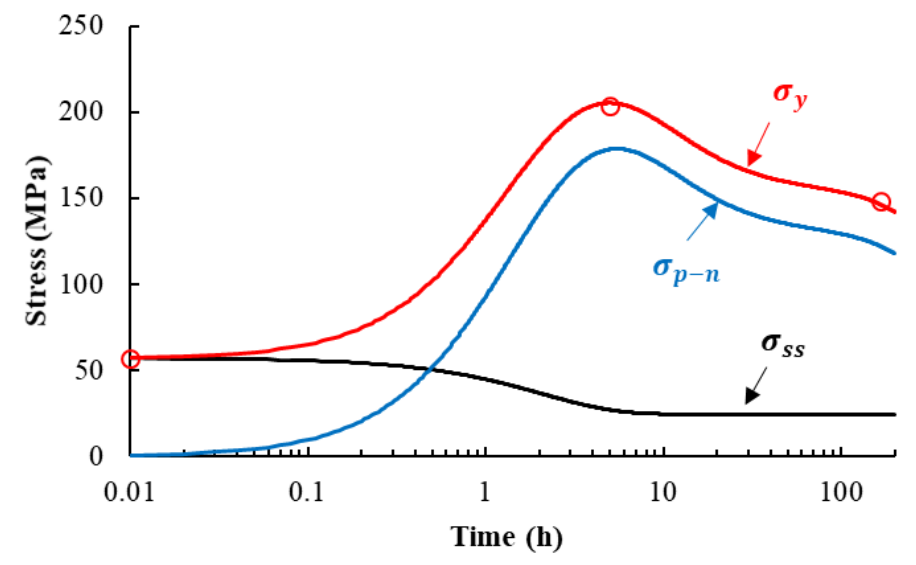

Figure 3. Comparison of evolutions of yield strength and corresponding strengthening components during artificial ageing of AA6063 at $185^{\circ} \mathrm{C}$ from experiments (symbols [33]) and modelling results from Table 1 (lines).

In addition, based on the detailed microstructural values at different artificial ageing states, the work hardening behaviour of AA6063 at the as-received state, peak-aged T6 state and over-aged T7 state can be predicted by the developed model as well, and the modelling results are compared with corresponding experimental results in Figure 4. The significant decreasing level of work hardening 
from as-quenched to T6 state has been successfully predicted, mainly due to the loss of solutes during artificial ageing [33]. While after peak-ageing, the work-hardening level experience only minor decrease from T6 to T7 states, which comes from the competitive of the decreasing statically stored dislocation density and increasing geometrically necessary dislocation from more coarsened precipitates, as predicted in Figure 2. All these results help to demonstrate the effectiveness of the proposed model for both microstructures and macro properties prediction of AA6063 during long-term artificial ageing.

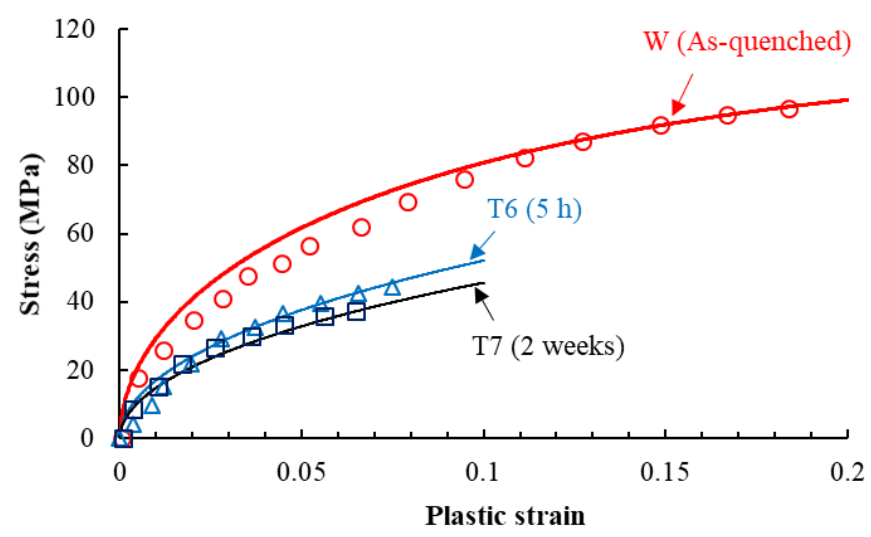

Figure 4. Comparison of the work hardening behaviour of AA6063 with different artificially aged states (time) at $185^{\circ} \mathrm{C}$ from experiments (symbols [33]) and modelling results from Table 1 (lines).

\section{2. $A A 2198$}

Figure 5 compares the evolutions of key microstructural variables of AA2198 during ageing at $155^{\circ} \mathrm{C}$ for up to $500 \mathrm{~h}$ from both experiments and models listed in Table 2, in which the quantified experimental data of precipitates were obtained from TEM analysis in [35]. For the newly nucleated precipitates, the normalised value of newly nucleated precipitates $\bar{r}_{n}$ increases to about 1 at around $16 \mathrm{~h}$, agrees well with the experimental results in [35], in which peak-ageing occurs at $16 \mathrm{~h}$. It has been reported that the radius of T1 precipitates in AA2198 tends to stay a constant level after peak-ageing, while thickness thickening starts for coarsening [23]. This behaviour has been predicted by the decreasing of aspect ratio $q$ value in Figure $5 \mathrm{a}$ after peak-ageing. While for the dissolving naturally-aged precipitate, both their radius $\left(\bar{r}_{d}\right)$ and volume fraction $\left(f_{d}\right)$ are decreased to 0 at around $2 \mathrm{~h}$. It also agrees well with corresponding experiments from [34]. While the solute concentration $\bar{c}$ experiences a slight increase at the first $2 \mathrm{~h}$ of ageing, due to the dissolution of naturally aged clusters and weak precipitates, and then decreases due to the nucleation and growth of new precipitates until reaching the equivalent level after peak-ageing.

The strengthening components and final yield strength values predicted by the model have been plotted and compared with experimental results in Figure 6 . The strengthening components evolves at a same trend with their corresponding microstructural variables in Figure 5. The initial decrease of yield strength $\left(\sigma_{y}\right)$ has been predicted due to the dissolution of precipitates, which leads to a decreasing $\sigma_{p-d}$ value at the first $2 \mathrm{~h}$ of ageing, and then reached to a near peak-state at around 10 to $20 \mathrm{~h}$, due to the significant strengthening effect from new precipitates, which demonstrates a fast and continuous increasing strengthening effect of $\sigma_{p-n}$ before $20 \mathrm{~h}$. It has been reported that the high yield strength at the peak-ageing state of AA2198 will be remained for a long time at the over-ageing states [34], which has been successfully predicted in Figure 6 due to the competition between the remained radius, slightly increasing volume fraction and decreasing aspect ratio, as predicted in Figure 5 . The final predicted yield strength shows an excellent agreement with corresponding experimental results, showing the effectiveness of the developed model. 


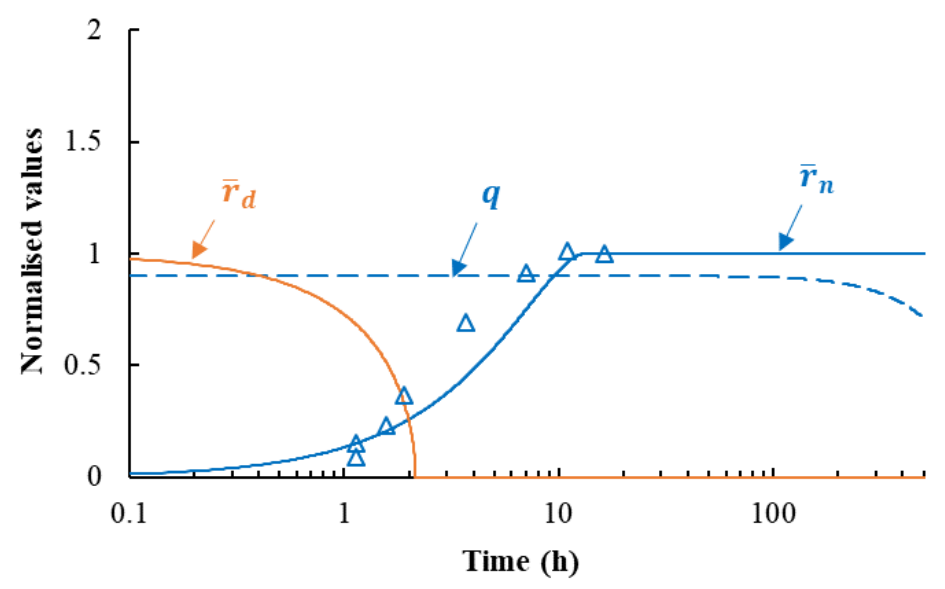

(a)

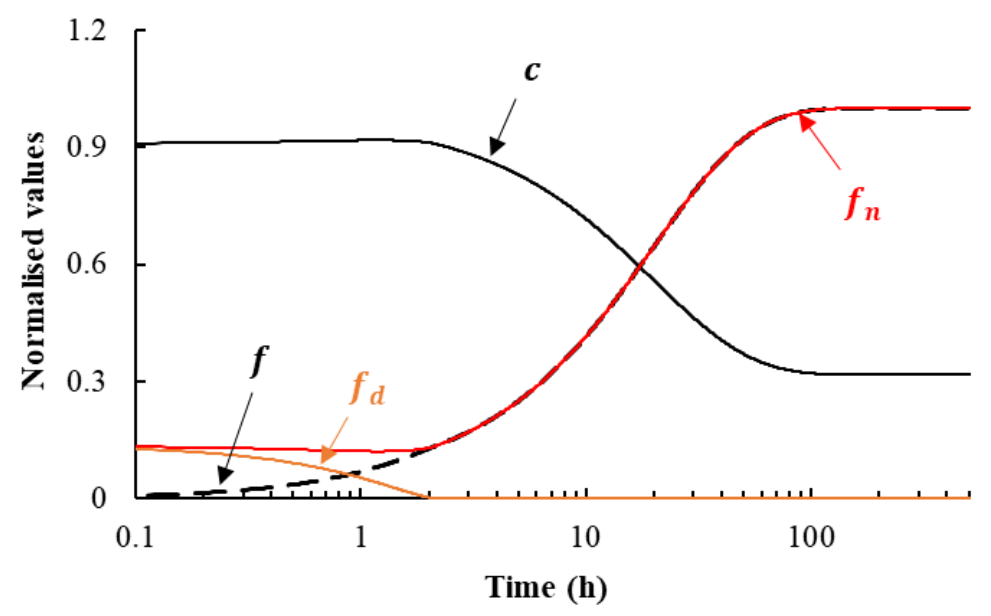

(b)

Figure 5. Comparison of evolutions of indicated microstructural variables during artificial ageing of AA2198 at $155{ }^{\circ} \mathrm{C}$ from experiments (symbols [35]) and modelling results from Table 3 (lines). (a) Variables of dimensions of precipitates; (b) Variables of volume fractions and solid solution.

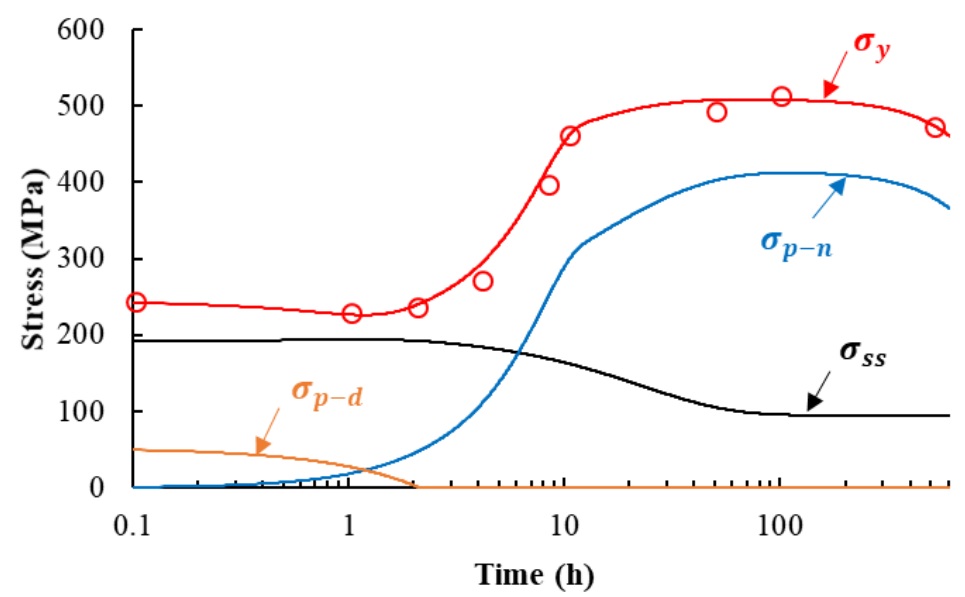

Figure 6. Comparison of evolutions of yield strength and corresponding strengthening components during artificial ageing of AA2198 at $155^{\circ} \mathrm{C}$ from experiments (symbols [34]) and modelling results from Table 3 (lines). 
With the developed model in this study, the work hardening behaviour of AA2198 after artificial ageing with various time durations from 0 to $500 \mathrm{~h}$ has been predicted based on the obtained microstructural variables, and some selected results are shown in Figure 7. A very good agreement between the experiments and models of the alloys after various ageing time for up to $500 \mathrm{~h}$ has been achieved. The work hardening level of AA2198 is affected by both the precipitates and solute concentrations in the alloy, which have been modelled by Equations (15) and (16). A higher level of solute concentration could enhance the work hardening level of the alloys, which has been well modelled in Figure 7. A slightly higher work hardening level is observed after $1 \mathrm{~h}$ ageing when compared with the as-received material, due to the increase of $\bar{c}$ from the dissolving precipitates in Figure 5. While with the subsequent ageing, the depletion of solid solutes and the nucleation and growth of precipitates leads to a decreasing level of work hardening in Figure 7.

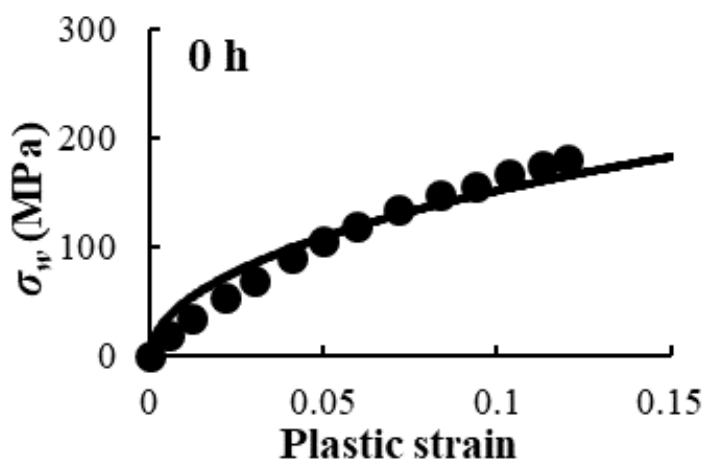

(a) $0 \mathrm{~h}$

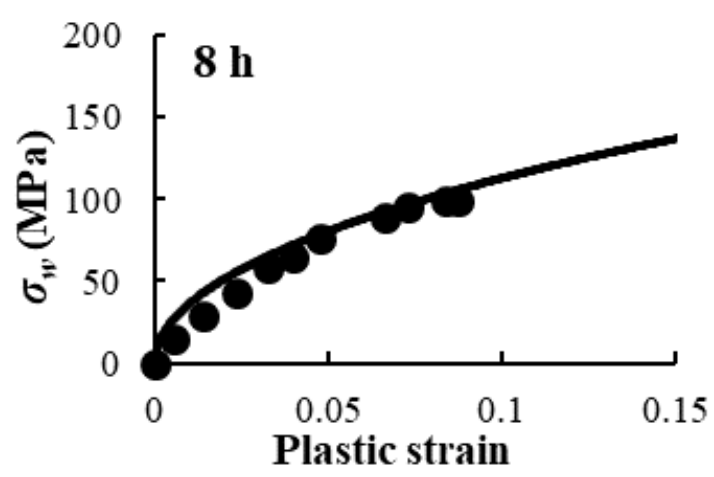

(c) $8 \mathrm{~h}$

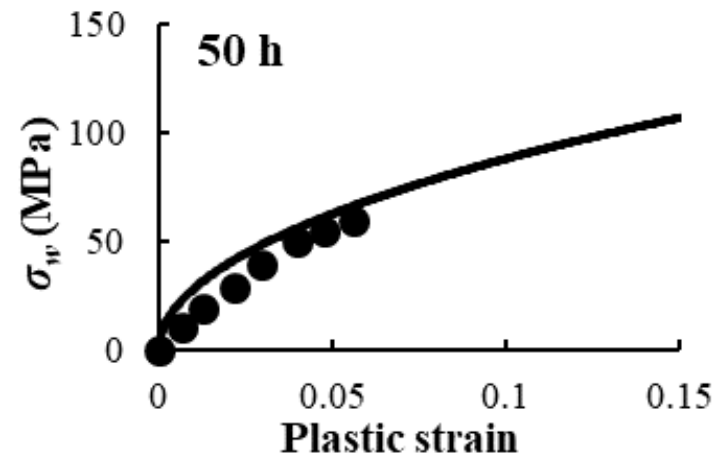

(e) $50 \mathrm{~h}$

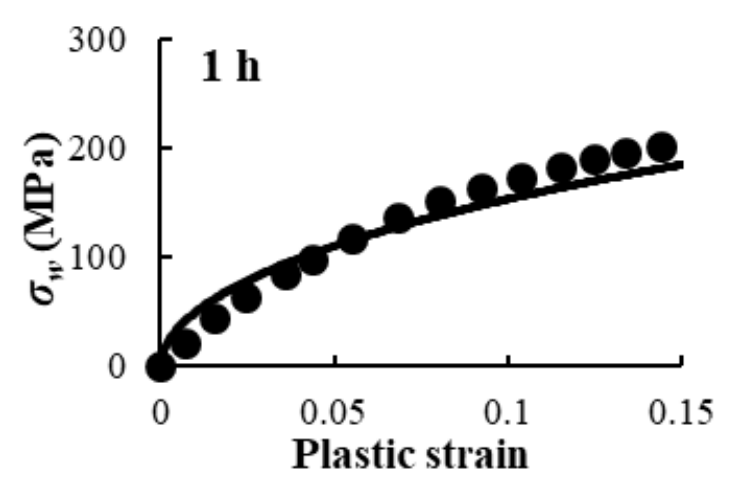

(b) $1 \mathrm{~h}$

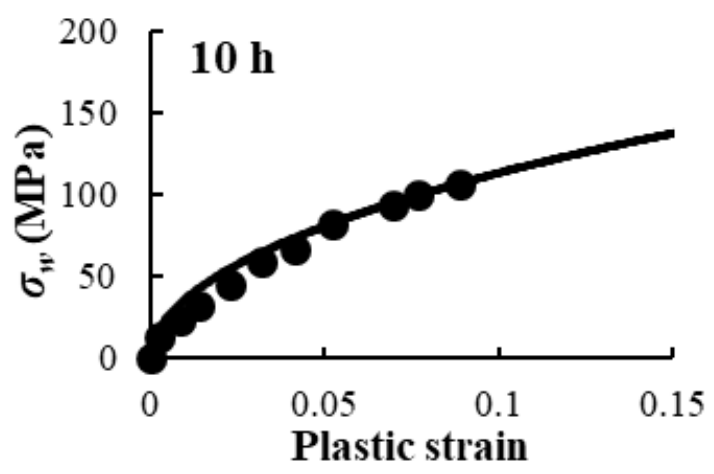

(d) $10 \mathrm{~h}$

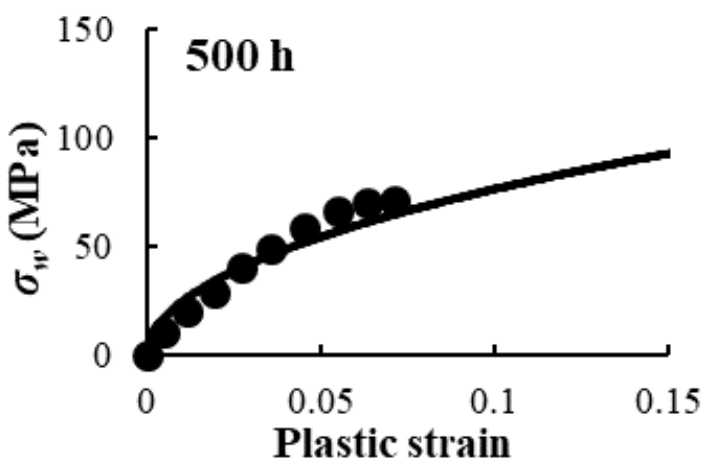

(f) $500 \mathrm{~h}$

Figure 7. Comparison of the work hardening behaviour of AA2198 with different artificially aged states (time) at $155^{\circ} \mathrm{C}$ from experiments (symbols [34]) and modelling results from Table 3 (lines): (a) not-aged; (b) 1 h aged; (c) 8 h aged; (d) 10h aged; (e) 50h aged and (f) 500h aged. 
Hence, all these application results indicate that the proposed model in Section 2 can be successfully applied to predict both the yield strength and work hardening behaviour of aluminium alloys during and after artificial ageing with various time durations from both sides of microstructures and macro-properties. Although the applications have only been demonstrated for AA6063 and AA2198, it has the capability to be used for ageing of other aluminium alloys containing sphere, plate or rod-shaped precipitates.

\section{Conclusions}

A unified constitutive model has been developed in this study to predict not only yield strength but also work hardening behaviour of various aluminium alloys during and after artificial ageing process considering different types of precipitates. Related microstructural data and mechanical properties during ageing of two representative aluminium alloys were utilised for calibration and validation. The following conclusions can be drawn:

(1) The dimensions of all the main types of precipitates (sphere, plate, rod) in various aluminium alloys have been generated by a primary dimension and aspect ratio, with which, a general form of equation has been developed for modelling of different precipitate types during ageing of heat treatable aluminium alloys.

(2) The effects of key microstructural variables, including precipitates (radius, aspect ratio, volume fraction) and solid solutes, on the yield strength during artificial ageing has been modelled, based on which, a set of equations has been further proposed to consider and include the effect of these microstructural variables on the work-hardening behaviour of the aged alloys. A whole set of unified constitutive model by combining these two sets of equations then has been developed, which can be used to concurrently predict both microstructures and macro-properties (yield strength and work hardening) for long-term aged aluminium alloys.

(3) The model has been successfully applied to predict the microstructures, yield strength and work hardening behaviour of two representative aluminium alloys (AA6063 and AA2198) after artificial ageing process from $0 \mathrm{~h}$ to up to $500 \mathrm{~h}$. The highly interacted effects among microstructures, yield strength and work hardening levels have been well predicted. It is believed that the model has the capability to be used for ageing of other heat treatable aluminium alloys with sphere, plate or rod-shaped precipitates.

Author Contributions: Conceptualization, K.J. and G.L.; methodology, K.J. and J.X.; validation, Y.S., H.C. and Y.L.; formal analysis, K.J.; investigation, K.C.; resources, G.L.; data curation, Y.Z.; writing—original draft preparation, K.J.; writing-review and editing, Y.L.; visualization, Y.S.; supervision, J.X.; project administration, K.J.; funding acquisition, K.J. All authors have read and agreed to the published version of the manuscript.

Funding: This research received no external funding.

Acknowledgments: The authors thank the Beijing Institute of Astronautical Systems Engineering for encouraging authors to take out this research. We are grateful to Yanmin Qu and Zhou Mu for their advices in choosing this study topic.

Conflicts of Interest: The authors declare no conflict of interest.

\section{References}

1. Miao, W.; Laughlin, D. Precipitation hardening in aluminum alloy 6022. Scr. Mater. 1999, 40, 873-878. [CrossRef]

2. Kaufman, J.G. Introduction to Aluminum Alloys and Tempers; ASM International: Cleveland, OH, USA, 2000.

3. Poole, W.; Lloyd, D.; Embury, J. The effect of natural ageing on the evolution of yield strength during artificial ageing for Al-Mg-Si-Cu alloys. Mater. Sci. Eng. A 1997, 234, 306-309. [CrossRef]

4. Proton, V.; Alexis, J.; Andrieu, E.; Delfosse, J.; Deschamps, A.; De Geuser, F.; Lafont, M.C.; Blanc, C. The influence of artificial ageing on the corrosion behaviour of a 2050 aluminium-copper-lithium alloy. Corros. Sci. 2014, 80, 494-502. [CrossRef] 
5. Li, Y.; Shi, Z.; Lin, J.; Yang, Y.L.; Saillard, P.; Said, R. Effect of machining-induced residual stress on springback of creep age formed AA2050 plates with asymmetric creep-ageing behaviour. Int. J. Mach. Tools Manuf. 2018, 132, 113-122. [CrossRef]

6. Marceau, R.K.; Sha, G.; Ferragut, R.; Dupasquier, A.; Ringer, S.P. Solute clustering in Al-Cu-Mg alloys during the early stages of elevated temperature ageing. Acta Mater. 2010, 58, 4923-4939. [CrossRef]

7. Wang, S.; Starink, M.; Gao, N. Precipitation hardening in Al-Cu-Mg alloys revisited. Scr. Mater. 2006, 54, 287-291. [CrossRef]

8. Alexopoulos, N.D.; Velonaki, Z.; Stergiou, C.I.; Kourkoulis, S.K. Effect of ageing on precipitation kinetics, tensile and work hardening behavior of Al-Cu-Mg (2024) alloy. Mater. Sci. Eng. A 2017, 700, 457-467. [CrossRef]

9. Deschamps, A.; Livet, F.; Brechet, Y. Influence of predeformation on ageing in an Al-Zn-Mg alloy-I. Microstructure evolution and mechanical properties. Acta Mater. 1998, 47, 281-292. [CrossRef]

10. Stiller, K.; Warren, P.J.; Hansen, V.; Angenete, J.; Gjønnes, J. Investigation of precipitation in an Al-Zn-Mg alloy after two-step ageing treatment at 100 and $150{ }^{\circ} \mathrm{C}$. Mater. Sci. Eng. A 1999, 270, 55-63. [CrossRef]

11. Sha, G.; Cerezo, A. Early-stage precipitation in Al-Zn-Mg-Cu alloy (7050). Acta Mater. 2004, 52, 4503-4516. [CrossRef]

12. Cai, M.; Field, D.; Lorimer, G. A systematic comparison of static and dynamic ageing of two Al-Mg-Si alloys. Mater. Sci. Eng. A 2004, 373, 65-71. [CrossRef]

13. Esmaeili, S.; Lloyd, D.; Poole, W. Modeling of precipitation hardening for the naturally aged Al-Mg-Si-Cu alloy AA6111. Acta Mater. 2003, 51, 3467-3481. [CrossRef]

14. Lin, J.; Liu, Y. A set of unified constitutive equations for modelling microstructure evolution in hot deformation. J. Mater. Process. Technol. 2003, 143, 281-285. [CrossRef]

15. Shercliff, H.; Ashby, M. A process model for age hardening of aluminium alloys-I. The model. Acta Metall. Mater. 1990, 38, 1789-1802. [CrossRef]

16. Esmaeili, S.; Lloyd, D.; Poole, W. A yield strength model for the Al-Mg-Si-Cu alloy AA6111. Acta Mater. 2003, 51, 2243-2257. [CrossRef]

17. Liu, G.; Zhang, G.J.; Ding, X.D.; Sun, J.; Chen, K.H. Modeling the strengthening response to aging process of heat-treatable aluminum alloys containing plate/disc-or rod/needle-shaped precipitates. Mater. Sci. Eng. A 2003, 344, 113-124. [CrossRef]

18. Li, Y.; Shi, Z.; Lin, J.; Yang, Y.-L.; Rong, Q. Extended application of a unified creep-ageing constitutive model to multistep heat treatment of aluminium alloys. Mater. Des. 2017, 122, 422-432. [CrossRef]

19. Starink, M.; Wang, S. A model for the yield strength of overaged Al-Zn-Mg-Cu alloys. Acta Mater. 2003, 51, 5131-5150. [CrossRef]

20. Kocks, U. Laws for Work-Hardening and Low-Temperature Creep. J. Eng. Mater. Technol. 1976, 98, 76-85. [CrossRef]

21. Deschamps, A.; Brechet, Y.; Necker, C.J.; Saimoto, S.; Embury, J.D. Study of large strain deformation of dilute solid solutions of Al-Cu using channel-die compression. Mater. Sci. Eng. A 1996, 207, 143-152. [CrossRef]

22. Kaneko, K.; Oyamada, T. A viscoplastic constitutive model with effect of aging. Int. J. Plast. 2000, 16, 337-357. [CrossRef]

23. Li, Y.; Shi, Z.; Lin, J. Experimental investigation and modelling of yield strength and work hardening behaviour of artificially aged Al-Cu-Li alloy. Mater. Des. 2019, 183, 108121. [CrossRef]

24. Lin, Y.C.; Jiang, Y.Q.; Liu, G.; Qin, S. Modeling the two-stage creep-aging behaviors of an Al-Cu-Mg alloy. Mater. Res. Express 2018, 5, 096514. [CrossRef]

25. Nayan, N.; Mahesh, S.; Prasad, M.J.; Murthy, S.V.; Samajdar, I. A phenomenological hardening model for an aluminium-lithium alloy. Int. J. Plast. 2019, 118, 215-232. [CrossRef]

26. Li, Y.; Shi, Z.; Lin, J.; Yang, Y.L.; Huang, B.M.; Chung, T.F.; Yang, J.R. Experimental investigation of tension and compression creep-ageing behaviour of AA2050 with different initial tempers. Mater. Sci. Eng. A 2016, 657, 299-308. [CrossRef]

27. Zhan, L.; Lin, J.; Dean, T.A.; Huang, M. Experimental studies and constitutive modelling of the hardening of aluminium alloy 7055 under creep age forming conditions. Int. J. Mech. Sci. 2011, 53, 595-605. [CrossRef]

28. Li, Y.; Shi, Z.; Lin, J.; Yang, Y.L.; Rong, Q.; Huang, B.M.; Chung, T.F.; Tsao, C.S.; Yang, J.R.; Balint, D.S. A unified constitutive model for asymmetric tension and compression creep-ageing behaviour of naturally aged Al-Cu-Li alloy. Int. J. Plast. 2017, 89, 130-149. [CrossRef] 
29. Zhang, J.; Deng, Y.; Zhang, X. Constitutive modeling for creep age forming of heat-treatable strengthening aluminum alloys containing plate or rod shaped precipitates. Mater. Sci. Eng. A 2013, 563, 8-15. [CrossRef]

30. Wu, L.; Ferguson, W.G. Modelling of precipitation hardening in casting aluminium alloys. Mater. Sci. Forum 2009, 618-619, 203-206. [CrossRef]

31. Zheng, J.H.; Lin, J.; Lee, J.; Pan, R.; Li, C.; Davies, C.M. A novel constitutive model for multi-step stress relaxation ageing of a pre-strained 7xxx series alloy. Int. J. Plast. 2018, 106, 31-47. [CrossRef]

32. Kocks, U.; Mecking, H. Physics and phenomenology of strain hardening: The FCC case. Prog. Mater. Sci. 2003, 48, 171-273. [CrossRef]

33. Khadyko, M.; Myhr, O.; Hopperstad, O. Work hardening and plastic anisotropy of naturally and artificially aged aluminium alloy AA6063. Mech. Mater. 2019, 136, 103069. [CrossRef]

34. Deschamps, A.; Decreus, B.; De Geuser, F.; Dorin, T.; Weyland, M. The influence of precipitation on plastic deformation of Al-Cu-Li alloys. Acta Mater. 2013, 61, 4010-4021. [CrossRef]

35. Decreus, B.; Deschamps, A.; De Geuser, F.; Donnadieu, P.; Sigli, C.; Weyland, M. The influence of Cu/Li ratio on precipitation in Al-Cu-Li-x alloys. Acta Mater. 2013, 61, 2207-2218. [CrossRef]

(C) 2020 by the authors. Licensee MDPI, Basel, Switzerland. This article is an open access article distributed under the terms and conditions of the Creative Commons Attribution (CC BY) license (http://creativecommons.org/licenses/by/4.0/). 